\title{
Otolith micro- and macrostructure analysis to improve accuracy of growth parameter estimation for white mullet Mugil curema
}

\author{
Francisco M. Santana ${ }^{1}$, Eric Morize ${ }^{2}$, Jacques Clavier ${ }^{3}$, Rosangela Lessa $^{1, *}$ \\ ${ }^{1}$ Laboratório de Dinâmica de Populações Marinhas (DIMAR), Departamento de Pesca e Aqüicultura (DEPAq), \\ Universidade Federal Rural de Pernambuco (UFRPE), Av. D. Manoel de Medeiros, s/n, Dois Irmãos, \\ Recife-PE, CEP 52171-900, Brazil \\ ${ }^{2}$ Laboratoire de Sclérochronologie des Animaux Aquatiques (LASAA), Institut de Recherche \\ pour le Développement (IRD), Centre IRD de Brest, Plouzané, France \\ ${ }^{3}$ Institut Universitaire Européen de la Mer (IUEM), Laboratoire des Sciences de l'Environnement Marin (LEMAR), \\ Plouzané, France
}

\begin{abstract}
Age and growth studies on the white mullet Mugil curema present (Valenciennes, 1836) dissimilarities with regard to the parameters estimated. It is therefore necessary to undertake a growth analysis based on micro- and macrostructures of otoliths from the species in order to reveal the cause of such dissimilarities. Microstructures were validated through otolith marking by balneation in alizarine complexone and demonstrated daily periodicity. Daily microstructures were observed in individuals up to $15.7 \mathrm{~cm}$ in fork length and exhibited 5 distinct growth zones. Zones I, II and III (62 d) composed the first macrostructure and Zone IV (223 d) composed the second. It was not possible to see microstructures in Zone $\mathrm{V}$ and, beginning with this zone, macrostructures were considered annual, based on the analysis of mean monthly marginal increments. Using daily microstructures and annual macrostructures, the von Bertalanffy function provided the following parameters: $L_{\infty}=34.4 \mathrm{~cm}, K=0.365$ and $t_{0}=0.311 \mathrm{yr}$. The following factors caused the dissimilarities between curves for white mullet: (1) absence of samples for ages $0^{+}$and $1 \mathrm{yr}$, which caused a high value of mean lengths for these age classes and a diminished $K$-value; $(2)$ the tendency toward overestimation at the age of 1 yr when estimated from macrostructures; (3) identification of the first 2 macrostructures as annual; and (4) absence of young-of-the-year specimens, causing $t_{0}$ to be significantly different from 0 . These factors lead to the underestimation of the parameters, which makes growth estimates imprecise.
\end{abstract}

KEY WORDS: Mugil curema · Otoliths · Age and growth · White mullet

\section{INTRODUCTION}

Mugilid species live in coastal estuarine areas in tropical and subtropical regions, where they are heavily exploited (Menezes 1983). In Brazil, mullets are generally called 'tainha' - a group of 7 highly valued species (Mugil platanus, M. curema, M. liza, $M$. gaimardianus, M. incilis, $M$. trichodon and $M$. curvidens) that yields around $2.8 \%$ of the total catch weight landed in Brazil and $5.2 \%$ of the total catch in the northeastern region of this country (IBAMA 2006). The white mullet $M$. curema occurs in the Atlantic Ocean from the United States to Argentina (Menezes 1983, Marin et al. 2003) and is the most abundant mugilid species in northeastern Brazil, accounting for $96.0 \%$ of the catch of all mullets in the region (Santana da Silva 2007). Juvenile white mullets - locally called 'saúna' — are captured in estuaries and shallow coastal areas, whereas adults are found at sea (Ditty \& Shaw 1996, Ibáñez \& Gutiérrez Benítez 2004). Overall, the exploitation of the white mullet relies strongly on the catch of juveniles within estuaries, which may account for 
$68.7 \%$ of the total catch of the species in certain areas along the northeastern coast (Santana da Silva 2007).

Age and growth of white mullet from the western Atlantic has been estimated in the United States, Mexico, Cuba and Venezuela from periodic rings of the spines of dorsal fins, scales and otoliths (Richards \& Castagna 1976, Alvarez-Lajonchère 1981, Ibáñez-Aguirre et al. 1995, 1999, Gallardo-Cabello et al. 2005), leading to rather dissimilar growth parameters. According to Santana da Silva (2007), dissimilarities have been attributed to: (1) the different hard structures used; (2) nonvalidated growth marks; or (3) the lack of the use of both micro- and macrostructures of otoliths.

Taking into account that coastal fishing resources along the Brazilian coast are now either fully exploited or overexploited (Lessa et al. 2006), caution should be taken when management decisions for the white mullet fishery are undertaken. Thus, as accurate age and growth information is needed as input data for agebased approaches used for stock assessments, the goal of the present study is to provide a validated growth curve based both on micro- and macrostructure analyses, which will allow reliable growth parameters for white mullet in northeastern Brazil for the required stock assessments.

\section{MATERIALS AND METHODS}

Specimens of white mullet were collected from landings of the artisanal fleet operating in the state of Pernambuco (northeastern Brazil) from November 2003 to January 2006. Catches were obtained from different types of gear, including beach seines, deep nets and gillnets. Moreover, tows using a beach net with a $5 \mathrm{~mm}$ mesh were carried out in estuaries in order to collect specimens smaller than those obtained from the commercial catches.

Sex and fork length (FL, $\mathrm{cm}$ ) were recorded from each specimen. Total length (TL) and standard length (SL) were converted to FL using the following equations (Santana da Silva 2007): FL $=0.8946 \mathrm{TL}+0.4645$ $\left(\mathrm{r}^{2}=0.9976\right)$ and $\mathrm{FL}=1.1345 \mathrm{SL}+0.4807\left(\mathrm{r}^{2}=0.9986\right)$. The pair of sagittal otoliths was removed and prepared for the micro- and macrostructure observations. In the first case, sections $<100 \mu \mathrm{m}$ in thickness were prepared from transverse sections (Campana \& Jones 1992, Wright et al. 2002a). The microstructure count was performed using transmitted light under light microscopy with 1000× magnification. For macrostructure analyses, images of the whole otolith were taken with the inner face turned upward under a binocular microscope using reflected light with $48 \times$ magnification. The distance between the nucleus and each macrostructure, as well as between the nucleus and the edge, were measured using TNPC software (Fablet \& Ogor 2005). Measurements were taken from the external edge of the translucent zones of each ring.

For validation purposes, different techniques were employed for the periodicity of microstructure estimation using alizarin complexone as a fluorescent marker (Wright et al. 2002b). Specimens were caught, transported and transferred alive to tanks from 150 to $1000 \mathrm{l}$ equipped with biological filters and aerators where fish were fed freely using spiruline microalgae rations. Out of 40 individuals, 27 , measuring from 2.8 to $21.0 \mathrm{~cm} \mathrm{FL,}$ survived to 2 balneations. In the first (6 December 2005), the specimens were contained for $12 \mathrm{~h}$ in an alizarin solution with seawater $\left(200 \mathrm{mg} \mathrm{l}^{-1}, \mathrm{pH} 7\right)$ neutralized with sodium hydroxide $(\mathrm{NaOH})$. For the second balneation (6 April 2006), the specimens were contained for $1 \mathrm{~d}$ in a solution with a $250 \mathrm{mg} \mathrm{l}^{-1}$ concentration of alizarin. The fish were then maintained in basins all together until death occurred.

Overall, individuals died between 0 and $69 \mathrm{~d}$ after the second marking. The otoliths were taken and thin sections were prepared. Counts of microstructures were performed under a microscope equipped with an epifluorescence device, using 400 and 1000× magnifications.

The mean number of days and microstructures counted after alizarin marking was compared using a chi-squared test. The coefficients $a$ and $b$ of the linear regression between the number of days and microstructures were compared by a Student's $t$-test, with $a=$ 0 and $b=1$ (Panfili \& Tomás 2001).

The microstructure count along the otolith section was carried out from the core towards the ventral edge up to a zone of cracks, where the microstructures are unclear and illegible. In this zone, the reading axis was modified, turning to the external face of the otolith (Fig. 1).

Macrostructure deposition periodicity was determined through semi-direct validation, analyzing monthly averages of the marginal increment ratio (MIR) (Panfili \& Morales-Nin 2002):

$$
M I R=\frac{O E-R_{\mathrm{x}}}{R_{\mathrm{x}}-R_{\mathrm{x}-1}}
$$

where $O E$ is the distance between the nucleus and otolith edge, $R_{\mathrm{x}}$ is the distance between the nucleus and the last complete macrostructure and $R_{\mathrm{x}-1}$ is the distance between the nucleus and the penultimate complete macrostructure.

Monthly variation of the percentage of opaque zones $(M I R>0.3)$, translucent zones $(M I R<0.3)$ and zones in the beginning of formation $(M I R=0)$ was assessed. Two counts were carried out for all otoliths, allowing count precision to be estimated through the average percentage of error (APE) (Beamish \& Fournier 1981): 


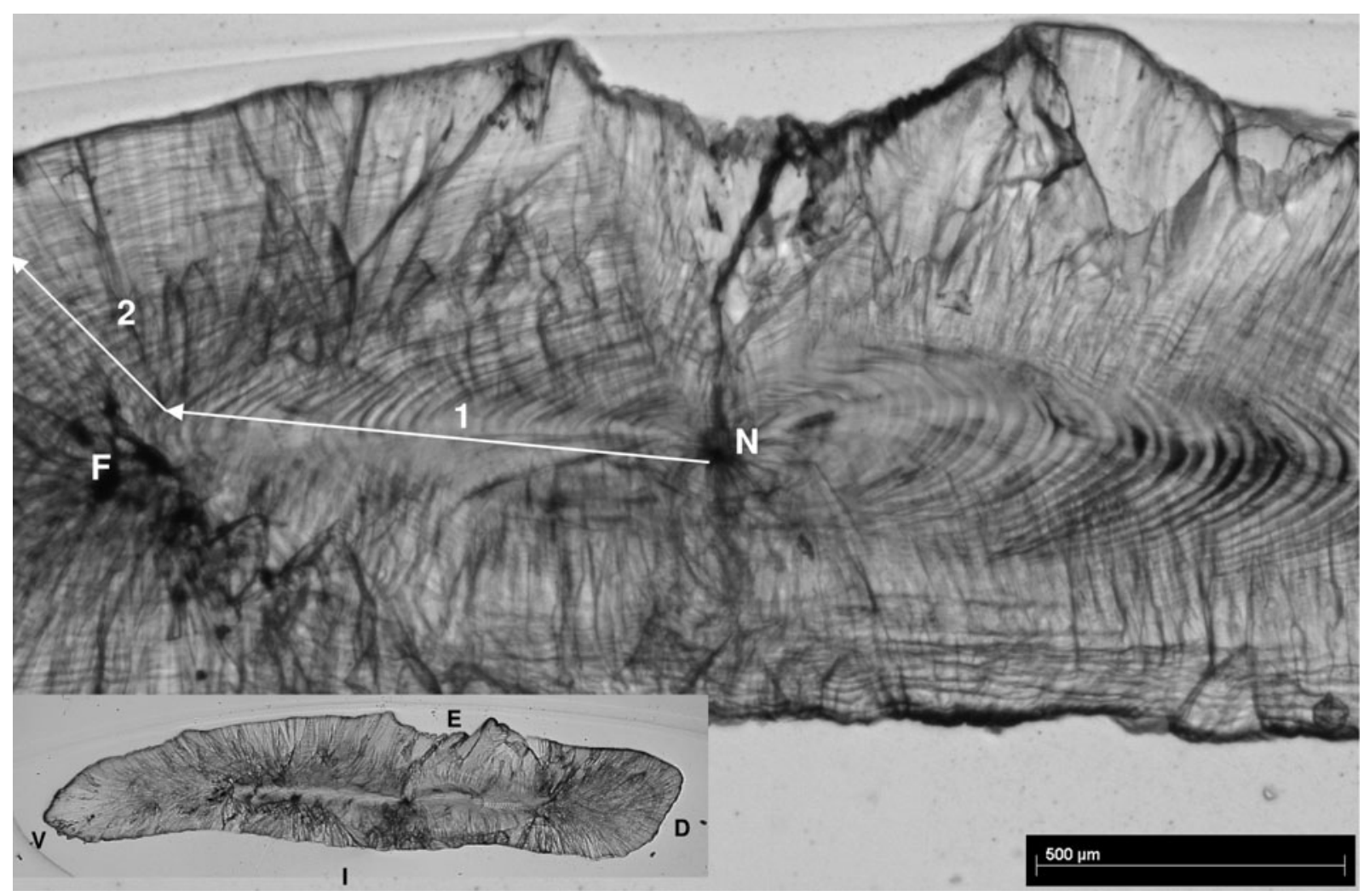

Fig. 1. Mugil curema. Cross-section of a $M$. curema otolith. White arrows are the reading axis of microstructures: (1) from the nucleus $(\mathrm{N})$ to the cracks $(\mathrm{F})$, and (2) to the external face. Inset: V and D: ventral and dorsal edges; E and I: external and internal face

$$
A P E=100 \% \times \frac{1}{R} \times \sum_{i=1}^{R} \frac{\left|X_{i j}-\overline{X_{j}}\right|}{\overline{X_{j}}}
$$

where $R$ is the number of readings, $X_{i j}$ the mean age of $j$ th at the $i$ th reading and $X_{j}$ the mean age calculated for the $j$ th reading.

For microstructures, the coefficient of variation (CV) (Campana 2001) was also estimated:

$$
\mathrm{CV}=100 \% \times \frac{\sqrt{\sum_{i=1}^{R} \frac{\left(X_{i j}-\overline{X_{j}}\right)^{2}}{R-1}}}{\overline{X_{j}}}
$$

A third microstructure count was performed for individuals with $A P E$ and $C V$ greater than $10 \%$. APE and $\mathrm{CV}$ were then recomputed and those that still exceeded $10 \%$ were removed from the analyses.

Linear and power correlations between otolith radius (measured from the core to the otolith edge) and FL were compared through the ANOVA (Fisher's F-test), which allowed the choice of the best fit to the data. Monastyrsky's back-calculation was used according to the best adjusted correlation (Francis 1990):

$$
L_{n}=\left(\frac{R_{n}}{O E}\right)^{a} \times L
$$

where $L_{n}$ is the back-calculated length at age $n, R_{n}$ the otolith radius at the time of the ring $n, O E$ the otolith edge, $L$ the length at capture and a the intercept on the length axis.

The von Bertalanffy (1938) equation was employed to describe the correlation between the size and age of fish:

$$
L_{t}=L_{\infty} \times\left[1-\mathrm{e}^{-\mathrm{k}\left(t-t_{0}\right)}\right]
$$

where $L_{t}$ is the predicted length at age $t, L_{\infty}$ the mean asymptotic total length, $K$ the coefficient of growth and $t_{0}$ the age when length is theoretically zero.

Comparisons of growth curves by sex were based on Cerrato (1990), whereas Munro's performance of growth $(\phi)$ (Sparre et al. 1989) was estimated to allow comparisons with other mugilid species:

$$
\phi=\log (K)+2 \log \left(L_{\infty}\right)
$$

The maximum age $\left(t_{\max }\right)$ that a fish can reach was calculated according to Fabens (1965):

$$
t_{\max }=\frac{5 \times[\ln (2)]}{K}
$$




\section{RESULTS}

A total of 521 otoliths were extracted from individuals between 1.3 and $39.5 \mathrm{~cm}$ FL. The best fit between the otolith length and fish length was obtained by a power relation, as with $\mathrm{R}^{2}=0.9632$.

\section{Analysis of micro- and macrostructures}

Thin sections of 292 otoliths were prepared for the microstructure counts. These otoliths were removed from fish between 1.3 and $35.6 \mathrm{~cm}$ FL. From the nucleus to the edge, 5 zones were identified according to the width and legibility of the microstructures.

Zone I is located around the core, extending to the first discernible microstructure seen under the optical microscope. There are no discernible microstructures within this zone and its mean $( \pm \mathrm{SD})$ width is $8.5 \pm$ $0.7 \mu \mathrm{m}_{i}$ the zone corresponds to embryo development within the egg. Zone II is formed by the 14 th to 20th (mean $=15$ ) first readable microstructures, the average width of which is $1.6 \pm 0.4 \mu \mathrm{m}$; the zone is discernible by its relatively darker color. Zone III is lighter in color than the preceding zone, with microstructures 2 times broader than that of the preceding zone (mean $\pm \mathrm{SD}=3.7 \pm 0.7 \mu \mathrm{m}$ ); this is the most readable part of the entire otolith and has about 47 microstructures (range $=42$ to 53). Microstructure width decreases in Zone IV when compared to the previous zone $($ mean $\pm \mathrm{SD}=1.7 \pm 0.5 \mu \mathrm{m})$; this zone is delimited by the last well-defined microstructure seen using a magnification of $1000 \times$. The maximum number of microstructures counted to the edge of this zone is 281. Zone $\mathrm{V}$ is a clear zone comprised of many cracks, which prevents any reading; this zone is present in otoliths of individuals $>15.0 \mathrm{~cm} \mathrm{FL}$, for which a total microstructure count is impossible. This explains the use of macrostructures for assigning the prediction of age for fish $>15.0 \mathrm{~cm}$ FL (47 individuals).

Regarding macrostructures, the first 2 correspond to Zones I to IV laid across the transverse section. The mean $( \pm \mathrm{SD})$ width for the first macrostructure is $0.6 \pm$ $0.04 \mathrm{~mm}$ and corresponds to Zones I, II and III, with about 62 microstructures. The largest individual fitting these conditions measured $9.3 \mathrm{~cm}$ FL. The mean width in the transverse section of the second macrostructure is $1.6 \pm 0.03 \mathrm{~mm}$, covering all of Zone IV; its external edge corresponds to individuals of $15.7 \mathrm{~cm} \mathrm{FL}$.

For individuals larger than $15.0 \mathrm{~cm} \mathrm{FL}$, for which otoliths were marked by balneation, the count of microstructures beyond the alizarin dye was not possible, as it corresponded to Zone $\mathrm{V}$, where readings failed due to numerous cracks.
There was no significant difference between the number of days $(N D)$ ( 6 to $115 \mathrm{~d}$, mean $=25.5 \mathrm{~d}$ ) and microstructures (NM) (7 to 112 microstructures, mean $=26.2$ microstructures) (Mann-Whitney $U$-test, $\mathrm{p}>$ 0.05). Moreover, the $a$ and $b$ coefficients of the linear regression between $N D$ and $N M=0.9632+1.8972, \mathrm{r}^{2}=$ $0.9960)$ confirms the daily deposition of microstructures ( $t$-test, $\mathrm{p}>0.05$ ).

The annual variation of $M I R$ reached a maximum in December and a minimum in January (Fig. 2). This sharp reduction suggests an annual deposition of macrostructures. Such a result is corroborated by the frequency of opaque and translucent zones on the edge of the otoliths. In January, the frequency of individuals starting to form a new macrostructure $(M I R=0)$ is high (Fig. 3). Thus it was considered that each macrostructure is formed annually, in January, except the first 2 macrostructures, which, according to the microstructure count, correspond to an average of $62 \mathrm{~d}$ for the first macrostructure and to $223 \mathrm{~d}$ for the second.

The mean $\mathrm{CV}$ of microstructures between 2 readings for the 229 fish analyzed was $4.6 \%(\mathrm{SD}=2.8 \%)$. The
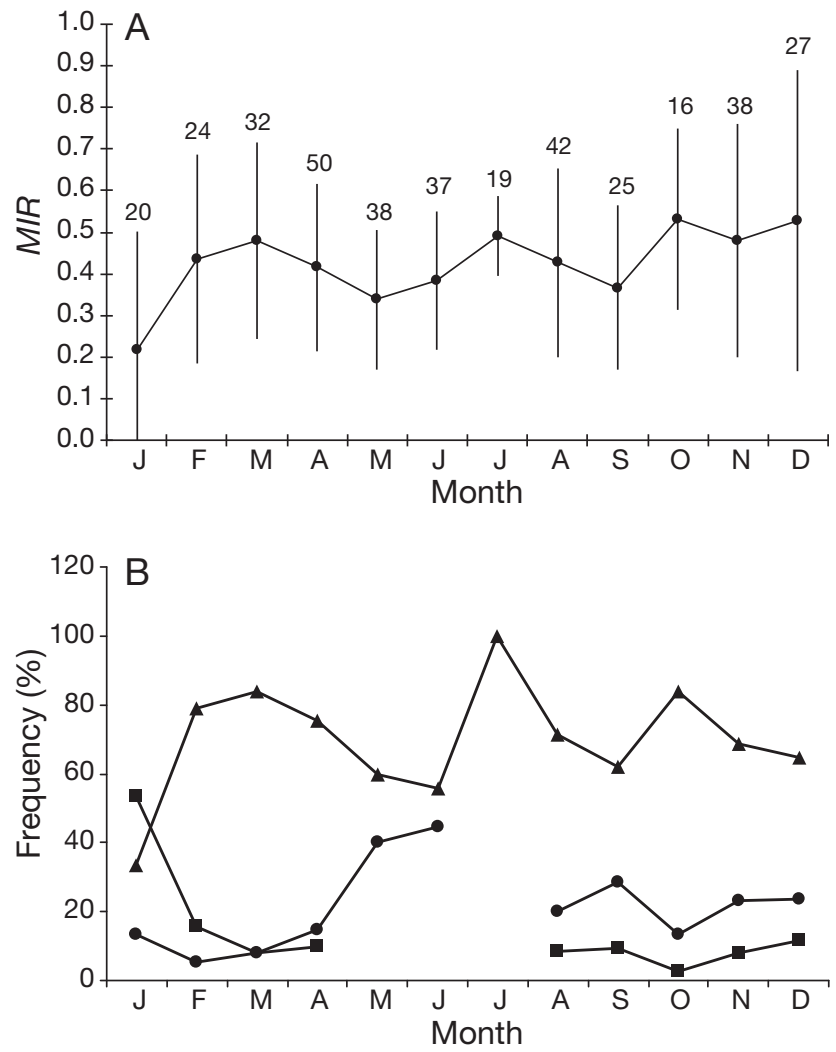

Fig. 2. Mugil curema. (A) Monthly marginal increment ratio $(M I R)$ of $M$. curema from Brazil, mean points \pm SD (vertical bars) and no. of ind. sampled for each month, and (B) relative frequency of individuals with the following marginal increments on the otolith edge: $M I R=0(\boldsymbol{\square})$; with 1 translucid zone $(M I R=0$ to $0.3 ; \boldsymbol{\bullet})$ and opaque zone $(M I R>0.3 ; \boldsymbol{\Delta})$ 


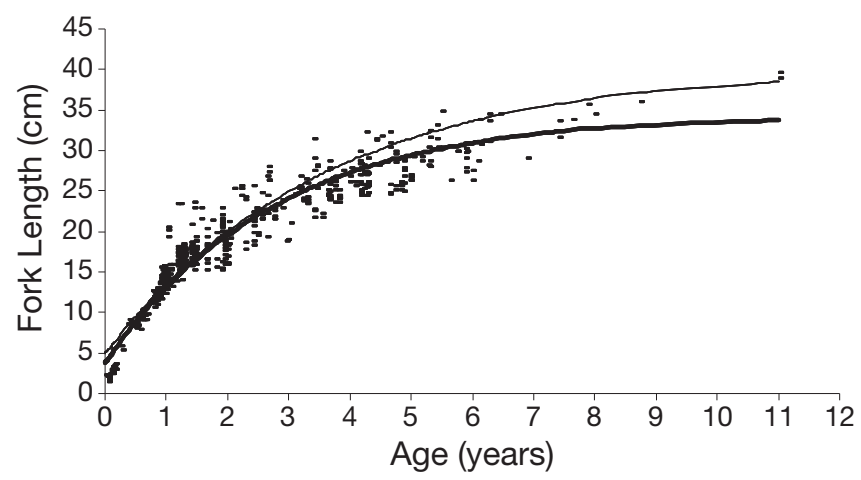

Fig. 3. Mugil curema. Growth curves for M. curema from Brazil, established according to the von Bertalanffy model, for relative age data (bold line) and back-calculated length (thin line)

$A P E$ between macrostructure readings was $5.7 \%$ $(\mathrm{SD}=1.5 \%)$.

According to mean back-calculated lengths, the size of the larvae at hatching - corresponding to Zone Iis $1.9 \mathrm{~mm}$ FL. The species ends the larval phase and enters the juvenile phase (Zone II) at $6.8 \mathrm{~mm}$ FL.

The formation of the first macrostructure-corresponding to Zone III - takes place on otoliths of 62day-old fish, with a mean back-calculated length of $3.5 \mathrm{~cm}$ FL. The second macrostructure (Zone IV) appears on fish with a mean back-calculated length of $9.7 \mathrm{~cm}$ FL, which roughly corresponds to the size of recruitment to fisheries (Table 1).

White mullet grows $16.5 \mathrm{~cm}$ the first year (backcalculated data), with an average growth rate through to the third year of $4.3 \mathrm{~cm} \mathrm{yr}^{-1}$. Between 4 and $9 \mathrm{yr}$ of age, this rate drops to $2.2 \mathrm{~cm} \mathrm{yr}^{-1}$. From age 9 onward, the growth rate decreases to $0.3 \mathrm{~cm} \mathrm{yr}^{-1}$. Microstructure counts for individuals between 1.2 (0.07 yr) and

Table 1. Mugil curema. Mean back-calculated length-at-age $(\mathrm{cm})$ and standard deviation (SD) for combined sexes of white mullet. FL: fork length

\begin{tabular}{|lcc|}
\hline Age $(\mathrm{yr})$ & Mean FL $(\mathrm{cm})$ & SD $(\mathrm{cm})$ \\
\hline 0.17 & 3.51 & 0.17 \\
0.61 & 9.75 & 0.40 \\
1 & 16.46 & 0.77 \\
2 & 21.34 & 1.12 \\
3 & 25.00 & 1.30 \\
4 & 27.73 & 1.44 \\
5 & 30.13 & 1.30 \\
6 & 32.55 & 1.52 \\
7 & 34.85 & 1.97 \\
8 & 36.35 & 2.03 \\
9 & 38.40 & - \\
10 & 38.70 & - \\
11 & 39.02 & 0.49 \\
\hline
\end{tabular}

$15.9 \mathrm{~cm} \mathrm{FL}(\sim 1 \mathrm{yr})$ were used to model the curve of growth (Table 1).

\section{Comparisons of the different data from von Bertalanffy growth functions (VBGF)}

The VBGF derived from back-calculations best explains the variability of data for both micro- and macrostructures. For back-calculations, however, only 13 pairs of data were used without taking into account the errors in age and length estimations. Curves established for micro- and macrostructures revealed an abrupt change in growth after $1 \mathrm{yr}$ of age. Although microstructures could be counted at an age close to $1 \mathrm{yr}$ (allowing the growth of the young individuals to be estimated), estimates based on macrostructures described the growth of larger individuals. The growth curve derived for the description of the entire life cycle of white mullet was based on the 2 types of structures combined (Fig. 3). Using periodic macrostructures and daily microstructures, the VBGF provided the following parameters: $L_{\infty}=34.4 \mathrm{~cm} ; K=0.365 ; t_{0}=-0.311 \mathrm{yr}$, whereas for back-calculated mean lengths (Table 1), the parameters derived were $L_{\infty}=40.2 \mathrm{~cm} ; K=0.281$; $t_{0}=-0.459$ yr (Fig. 3).

The comparison of growth by sex was carried out using individuals larger than $18.0 \mathrm{~cm} \mathrm{FL}$, the gonads of which were identifiable (129 females, 19.8 to $39.5 \mathrm{~cm}$; 118 males, 18.4 to $31.4 \mathrm{~cm}$ ). As there was no significant difference between sexes according to the likelihood analysis (Table 2), both sexes were grouped together for growth estimation.

White mullet grows quickly (VBGF) during the first 2 yr of life, reaching $19.5 \mathrm{~cm}$ FL. The growth rate then quickly decreases until $30.0 \mathrm{~cm}$ FL (5 to 6 yr), attaining a rate of $2.0 \mathrm{~cm} \mathrm{yr}^{-1}$. Finally, growth rate slows to 0.4 $\mathrm{cm} \mathrm{yr}^{-1}$. The $L_{\infty}$ value is smaller than the maximum size of the largest individuals in the sample (39.5 cm FL). The performance of growth $(\phi)$ is 2.63 and longevity $\left(t_{\max }\right)$ is $9.5 \mathrm{yr}$.

Table 2. Likelihood ratio tests comparing estimates of von Bertalanffy parameters for males (a) and females (b) for white mullet within linear constraints. See 'Materials and methods' for parameter definitions. Not significant: $p>0.05$

\begin{tabular}{|lcccc|}
\hline Hypothesis & Linear constraints & Residual SS & df & $\mathrm{p}$ \\
\hline$H \Omega$ & None & 1541.35 & & \\
$H \omega_{1}$ & $L_{\infty \mathrm{a}}=L_{\infty \mathrm{b}}$ & 1700.85 & 1 & $>0.05$ \\
$H \omega_{2}$ & $K_{\mathrm{a}}=K_{\mathrm{b}}$ & 1611.68 & 1 & $>0.05$ \\
$H \omega_{3}$ & $t_{0 \mathrm{a}}=t_{0 \mathrm{~b}}$ & 1555.22 & 1 & $>0.05$ \\
$H \omega_{4}$ & $L_{\infty \mathrm{a}}=L_{\infty \mathrm{b}}$ & 3448.90 & 3 & $>0.05$ \\
& $K_{\mathrm{a}}=K_{\mathrm{b}}, t_{0 \mathrm{a}}=t_{0 \mathrm{~b}}$ & & & \\
\hline
\end{tabular}




\section{DISCUSSION}

Microstructures in otoliths from white mullet validated by fluorescent alizarin dyes reveal a daily formation pattern, as indicated by Marin et al. (2003), who counted microstructures in individuals in captivity. Alvarez-Lajonchère (1981) and Ibáñez-Aguirre \& Gallardo-Cabello (1996) demonstrated an annual formation of macrostructures coinciding with spawning in Cuba and Mexico. This pattern fits the present study as well, revealing that new macrostructures are deposited in the period from January to February, which closely follows the spawning period (November to February) (Santana da Silva 2007).

The discrimination of different growth zones by the microstructure width is important for the description of the initial phases, as their width is proportional to the growth of the fish (Campana \& Neilson 1985). Fertilized eggs from white mullet developed in captivity have an average overall length of $2.2 \mathrm{~mm}$ upon hatching (Houde et al. 1976). In the present study, back-calculated FL in microstructures from Zone I (described as the time before hatching) corresponded to $1.9 \mathrm{~mm}$, which is similar to that observed by Houde et al. (1976).

Throughout Zone II, corresponding to the larval phase (Houde et al. 1976), the first 15 microstructures were observed, a similar finding to that described by Marin et al. (2003), who counted 14. According to Houde et al. (1976), the metamorphosis from larva into juvenile occurs between 12 and $16 \mathrm{~d}$, corresponding to an estimated FL of 6.0 to $7.0 \mathrm{~mm}$ - a size similar to that in the present study $(6.8 \mathrm{~mm})$.

Microstructures in Zone III coincide with the deposition of the first non-annual macrostructure in 62day-old specimens of $3.5 \mathrm{~cm} \mathrm{FL}$, according to backcalculated size. The result is similar for another study, where after $36 \mathrm{~d}$, white mullet reach $3.2 \mathrm{~cm}$ FL, which results in an average growth rate of $0.073 \mathrm{~cm} \mathrm{~d}^{-1}$ (Houde et al. 1976). In the present study, the size of individuals estimated by Zone III ranged from 2.9 to $3.7 \mathrm{~cm} \mathrm{FL}$, leading to a lower growth rate $\left(0.057 \mathrm{~cm} \mathrm{~d}^{-1}\right)$ than that described by Houde et al. (1976). This zone, corresponding to the broadest microstructure of the otolith, indicates fast growth, which characterizes the period before recruitment to fisheries.

The second macrostructure was also found to be non-annual and deposited in the end of Zone IV. Throughout this zone, width and legibility of the microstructures decrease. The average individuals throughout this zone were 9.2 to $15.9 \mathrm{~cm} \mathrm{FL}$, corresponding to a mean age of $223 \mathrm{~d}$. These results are similar to those described by Marin et al. (2003), who found the average FL of juveniles in this zone was $14.7 \mathrm{~cm}$.

The first macrostructure considered as annual appears when sizes larger than $15.7 \mathrm{~cm}$ FL are reached. From the age of 1 to 3 yr (age at maturity), growth is very fast. However, after maturation until $9 \mathrm{yr}$ of age, the growth rate drops to half and continues to decrease until the end of life. The growth pattern for white mullet, including the juvenile phase, has not yet been fully described in the literature; previous studies have either not taken into account growth during the first year of life or have considered the 2 first macrostructures as annual.

Using otoliths, Ibáñez-Aguirre et al. $(1995,1999)$ estimated mean back-calculated FL for age $0^{+}$white mullet ranging from 16.8 to $17.2 \mathrm{~cm}$, which reveals an overestimation when compared to our results (mean back-calculated FL for age $0^{+}$was $6.6 \mathrm{~cm}$ ). On the basis of scales for the same age class, Ibáñez-Aguirre \& Gallardo-Cabello (1996) and Gallardo-Cabello et al. (2005) estimated mean back-calculated lengths of 15.7 and 9.9 $\mathrm{cm}$, respectively. An identical context exists when age 1 is concerned, as the lack of young-of-the-year specimens in samples leads to an overestimation of mean back-calculated sizes for both age $0^{+}$and age 1 .

Comparing the ages estimated from the micro- and macrostructures on hake Merluccius merluccius, Gor-

Table 3. Parameters of the von Bertalanffy model ( $L_{\infty} K$ and $t_{0 i}$ see 'Materials and methods' for parameter definitions), Munro's performance of growth $(\phi)$ and maximum age $\left(t_{\max }\right)$ for white mullet, according to different studies using various calcified structures. Ot: otoliths; Ds: dorsal fin spine; Sc: scales

\begin{tabular}{|lcccccl|}
\hline Calcified structure & $L_{\infty}$ & $K$ & $t_{0}$ & $\phi$ & $t_{\max }$ & \multicolumn{1}{c|}{ Source } \\
\hline Sc & 36.0 & 0.78 & -0.06 & 3.10 & 4.4 & Richards \& Castagna (1976) \\
Ds & 53.2 & 0.10 & -5.90 & 2.45 & 34.7 & Alvarez-Lajonchère (1981) \\
Sc & $40.0^{\mathrm{a}}$ & 0.16 & -3.84 & 2.41 & 21.5 & Ibáñez-Aguirre \& Gallardo-Cabello (1996) \\
Ot & $46.1^{\mathrm{a}}$ & 0.14 & -3.62 & 2.47 & 24.8 & Ibáñez-Aguirre et al. (1999) \\
$\mathrm{Sc}$ & $36.5^{\mathrm{a}}$ & 0.22 & -1.56 & 2.46 & 15.8 & Gallardo-Cabello et al. (2005) \\
Ot & 34.4 & 0.37 & -0.31 & 2.63 & 9.5 & Present study (micro- and macrostructures) \\
Ot & 40.2 & 0.28 & -0.46 & 2.66 & 12.3 & Present study (back-calculated fork length) \\
atal length & & & & & & \\
\hline
\end{tabular}




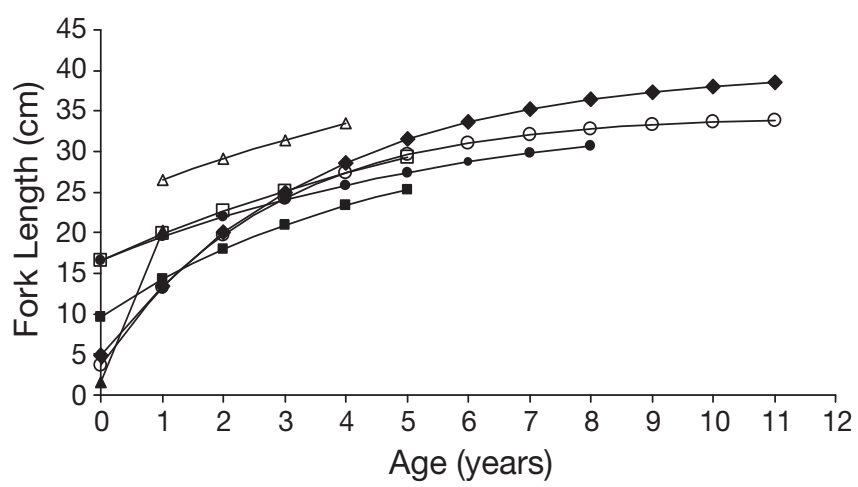

Fig. 4. Mugil curema. Growth curves for M. curema, established according to the von Bertalanffy model, from ( $\mathbf{\Delta})$ Richards \& Castagna (1976); ( $\Delta$ ) Alvarez-Lajonchère (1981); (•) Ibáñez-Aguirre \& Gallardo-Cabello (1996); () IbáñezAguirre et al. (1999); (匹) Gallardo-Cabello et al. (2005); and the present study ( back-calculated length; O: relative age)

doa et al. (2001) observed that there is an $\sim 18 \%$ tendency to overestimate the age of young individuals (1 yr) between the 2 structures. Using spines of the dorsal fin in Cuba, Alvarez-Lajonchère (1981) estimated a size of $23.2 \mathrm{~cm}$ FL for the first year of life. For the same age in México, Ibáñez-Aguirre et al. (1995, 1999) and Ibáñez-Aguirre \& Gallardo-Cabello (1996) also obtained a mean back-calculated length of about $20.6 \mathrm{~cm}$ FL. This size is larger than that obtained in the present study (16.5 cm FL).

VBGF parameters derived from back-calculation are similar to those estimated by Ibáñez-Aguirre et al. (1995, 1999) and Ibáñez-Aguirre \& Gallardo-Cabello (1996). However, the inclusion of 2 age classes with periodicity distinct from annual periodicity (macrostructure 1, $0.17 \mathrm{yr}$; macrostructure 2, $0.61 \mathrm{yr}$ ) led to a higher $K$-value and lower $t_{0}$ in the present study. $L_{\infty}$ obtained for back-calculated VBGF had a compatible value with that expected for the species. However, the lack of the smallest individuals, the age of which was assessed through daily microstructures, impeded a suitable fit, as obtained in the present study.

As young-of-the-year specimens have the highest growth for white mullet, back-calculated growth curves are not the best representation of growth for the entire life cycle when this age class $\left(0^{+}\right)$is absent, leading to an underestimation of the $K$-value (Table 3). The opposite occurs when only very young individuals are analyzed, as in the case of Richards \& Castagna (1976), who included individuals from 2.5 to $14.2 \mathrm{~cm}$ FL (<1 yr old) in the growth curve and obtained a higher $K$-value than those described by any other author (Table 3), bringing about an overestimation of $K$, as the VBGF is biased towards specimens with fast growth.
According to von Bertalanffy (1938), the $t_{0}$ value is intended to provide a better mathematical fit of data near the origin of the growth curve. In the present study, an inverse relationship between $K$ and $t_{0}$ values was found. Thus the highest is the former parameter, and the lowest (and closest to zero) is the latter (Table 3). The proximity of the $t_{0}$ value to 0 indicates that the curve represents growth from the moment zero.

The presence of individuals in the present study with sizes close to those in the larval phase led to an estimation of $t_{0}$ that was not significantly different from zero (student's $t$-test, $\mathrm{p}>0.05$ ), demonstrating that the growth curve starts quite near the origin (Fig. 4). Thus growth curves from the present study and Richards \& Castagna (1976) were the only ones to describe growth from the origin, whereas in Alvarez-Lajonchère (1981), Ibáñez-Aguirre \& Gallardo-Cabello (1996), IbáñezAguirre et al. (1999) and Gallardo-Cabello et al. (2005), the growth curve intercepts the y-axis at around $10 \mathrm{~cm}$, which is well above the origin.

The inclusion of fish of all sizes in age and growth studies results in a more representative growth curve for the species of interest across its entire life cycle as well as estimates of longevity and growth rate for different phases of development of white mullet. These estimates are particularly important for the calculation of biomass and recruitment in fisheries.

Acknowledgements. The authors thank the Conselho Nacional de Desenvolvimento Cientifico e Tecnologico (CNPq) and Institut de Recherche pour le Développement (IRD), which provided research grants and a PhD scholarship to F.M.S. A bilateral cooperation held by CNPq/IRD provided the means for the exchange of researchers. Special thanks are addressed to L. Marec and E. Dabas (IRD, Plouzané) and A. Ogor of Institut Français de Recherche pour l'Exploitation de la Mer (IFREMER). Remarks by anonymous reviewers led to substantial improvements to the manuscript; we greatly appreciate their careful and constructive comments.

\section{LITERATURE CITED}

Alvarez-Lajonchère L (1981) Determination de la edad y el crecimiento de Mugil liza, $M$. curema, $M$. hospes y $M$. trichodon (Pisces, Mugilidae) en aguas cubanas. Rev Invest Mar 2:142-162

Beamish RJ, Fournier DA (1981) A method for comparing the precision of a set of age determination. Can J Fish Aquat Sci 38:982-983

Campana SE (2001) Accuracy, precision and quality control in age determination, including a review of the use and abuse of age validation methods. J Fish Biol 59: $197-242$

Campana SE, Jones CM (1992) Analysis of otolith microstructure data. In: Stevenson DK, Campana SE (eds) Otolith microstructure examination and analysis. Can Spec Pub Fish Aquat Sci 117:73-100

> Campana SE, Neilson JD (1985) Microstructures of fish otoliths. Can J Fish Aquat Sci 42:1014-1032 
Cerrato RM (1990) Interpretable statistical tests for growth comparisons using parameters in the von Bertalanffy equation. Can J Fish Aquat Sci 47:1416-1426

Ditty JG, Shaw RF (1996) Spatial and temporal distribution of larval striped mullet (Mugil cephalus) and white mullet (M. curema, Family: Mugilidae) in the northern Gulf of Mexico, with notes on mountain mullet, Agonostomus monticola. Bull Mar Sci 59:271-288

Fabens AJ (1965) Properties and fitting of the von Bertalanffy growth curve. Growth 29:265-289

Fablet R, Ogor A (2005) TNPC (digital processing of calcified structures): user manual. Available at www.ifremer.fr/ lasaa/TNPC/tnpc4_2.htm

Francis RICC (1990) Back-calculation of fish length: a critical review. J Fish Biol 36:883-902

Gallardo-Cabello M, Cabral-Solís E, Espino-Barr E, IbáñezAguirre AL (2005) Growth analysis of white mullet Mugil curema (Valenciennes, 1836) (Pisces: Mugilidae) in the Cuyutlán Lagoon, Colima, México. Hidrobiologica 15: 321-325

Gordoa A, Raventos N, Dealie F (2001) Comparison between micro- and macro-structure readings in the age estimations of cape hake. J Fish Biol 59:1153-1163

Houde ED, Berkeley SA, Klinovsky JJ, Schekter RC (1976) Culture of larvae of the white mullet, Mugil curema Valenciennes. Aquaculture 8:365-370

IBAMA (Instituto Brasileiro de Meio Ambiente e dos Recursos Naturais Renováveis) (2006) Monitoramento da atividade pesqueira no litoral do Brasil. www.icmbio.gov.br/cepene/ index.php2_menu=61

Ibáñez AL, Gutiérrez-Benítez O (2004) Climate variables and spawning migrations of the striped mullet and white mullet in the north-western area of the Gulf of Mexico. J Fish Biol 65:822-831

Ibáñez-Aguirre AL, Gallardo-Cabello M (1996) Age determination of the grey mullet Mugil cephalus L. and the white mullet Mugil curema V. (Pisces: Mugilidae) in Tamihua Lagoon, Veracruz. Cienc Mar 22:329-345

Ibáñez-Aguirre AL, Gallardo-Cabello M, Sáchez-Rueda MP (1995) Estimation de la edad de la lisa Mugil cephalus y la lebrancha $M$. curema por métodos indirectos. Hidrobiologica 5:105-111

Ibáñez-Aguirre AL, Gallardo-Cabello M, Carrara XC (1999) Growth analysis of striped mullet, Mugil cephalus, and

Editorial responsibility: Hans Heinrich Janssen, Oldendorf/Luhe, Germany white mullet, $M$. curema (Pisces: Mugilidae), in the Gulf of Mexico. Fish Bull 97:861-872

Lessa R, Vieira ACS, Monteiro A, Santos JS and others (2006) Diagnóstico da pesca no litoral do estado de Pernambuco. In: Isaac VJ, Martins AS, Haimovici M, Andriguetto Filho JM (eds) A pesca marinha e estuarina do Brasil no início do século XXI: recursos, tecnologias, aspectos socioeconômicos e institucionais. Editora Universitária UFPA, Belém, p 67-91

Marin BJ, Quintero A, Bussiere D, Dodson JJ (2003) Reproduction and recruitment of white mullet (Mugil curema) to a tropical lagoon (Margarita Island, Venezuela) as revealed by otolith microstrucutre. Fish Bull 101:809-821

Menezes NA (1983) Guia prático para conhecimento e identificação das tainhas e paratis (Pisces, Mugilidae) do litoral brasileiro. Rev Bras Zool 2:1-12

Panfili J, Morales-Nin B (2002) Semi-direct validation. In: Panfili J, de Pontual H, Troadec H, Wright PJ (eds) Manual of fish sclerochronology. Ifremer-IRD, Plouzané, p 129-134

Panfili J, Tomás J (2001) Validation of age estimation and back-calculation of fish length based on otolith microstructures in tilapias (Pisces, Cichlidae). Fish Bull 99: 139-150

Richards CE, Castagna M (1976) Distribution, growth, and predation of juveniles white mullet (Mugil curema) in oceanside waters of Virginia's eastern shore. Chesapeake Sci 17:308-309

Santana da Silva FM (2007) Biologie, pêche et dynamique de la population de mulet blanc (Mugil curema, Valenciennes, 1836) de Pernambuco - Brésil. PhD thesis, Université de Bretagne Occidentale, Plouzané

Sparre P, Ursin E, Venema SC (1989) Introduction to tropical fish stock, Part 1. FAO Fish Tech Pap No. 306.1, FAO, Rome

von Bertalanffy L (1938) A quantitative theory of organic growth (inquiry on growth laws II). Hum Biol 10:181-213

Wright PJ, Panfili J, Morales-Nin B, Geffen AJ (2002a) Otoliths. In: Panfili J, de Pontual $\mathrm{H}$, Troadec $\mathrm{H}$, Wright PJ (eds) Manual of fish sclerochronology. Ifremer-IRD, Plouzané, p 31-57

Wright PJ, Panfili J, Folkvord A, Mosegaard H, Meunier FJ (2002b) Direct validation. In: Panfili J, de Pontual $\mathrm{H}_{\text {, }}$ Troadec $\mathrm{H}$, Wright PJ (eds) Manual of fish sclerochronology. Ifremer-IRD, Plouzané, p 114-128

Submitted: May 8, 2009; Accepted: September 4, 2009

Proofs received from author(s): October 16, 2009 